\title{
Comparison of the point-of-care blood gas analyzer versus the laboratory auto-analyzer for the measurement of electrolytes
}

\author{
Anunaya Jain • Imron Subhan • Mahesh Joshi
}

Received: 8 October 2008 / Accepted: 27 January 2009/Published online: 24 February 2009

(C) Springer-Verlag London Ltd 2009

\begin{abstract} and auto-analyzers.

\footnotetext{
A. Jain $(\triangle)$

College of Medicine, Mayo Clinic,

Rochester, MN, USA

e-mail: erjain@yahoo.co.in

I. Subhan $\cdot$ M. Joshi

Department of Emergency Medicine,

Apollo Health City, Hyderabad, India

I. Subhan

e-mail: imronsubhan@gmail.com

M. Joshi

e-mail: mahajosh@rediffmail.com
}

Background Electrolyte values are measured both by arterial blood gas (ABG) analyzers and central laboratory auto-analyzers (AA), but a significant time gap exists between the availability of both these results, with the $\mathrm{ABG}$ giving faster results than the AA. The authors hypothesized that there is no difference between the results obtained after measurement of electrolytes by the blood gas

Methods After approval by the ethics committee, an observational cohort study was conducted in which 200 paired venous and arterial samples from patients admitted to the Medical Intensive Care Unit (ICU) of Apollo Hospital, Hyderabad, India, were analyzed for electrolytes on the ABG machine and the AA. Analyses were done on the ABL555 blood gas analyzer and the Dade Dimension RxL Max, both located in the central laboratory. Statistical analyses were performed using paired Student's t test.

Results A total of 200 paired samples were analyzed. The mean ABG sodium value was 131.28 (SD 7.33), and the mean AA sodium value was 136.45 (SD 6.50) $(\mathrm{p}<0.001)$. The mean ABG potassium value was 3.74 (SD 1.92), and the mean AA potassium value was 3.896 (SD 1.848) $(\mathrm{p}=0.2679)$.

Conclusion Based on the above analysis, the authors found no significant difference between the potassium values measured by the blood gas machine and the auto-analyzer. However, the difference between the measured sodium was found to be significant. We therefore conclude that critical decisions can be made by trusting the potassium values obtained from the arterial blood gas analysis.

\section{Introduction}

Point-of-care testing enables clinicians to initiate appropriate treatment for emergent conditions, thereby benefitting the patient both clinically and economically [1].

Electrolyte values are conventionally measured for all critical patients who present to the emergency department, for patients receiving fluid therapy, and for patients admitted to intensive care units (ICU).

Routinely, all electrolytes are measured from serum by the auto-analyzers (AA) available in central laboratories of hospitals; however, this is time-consuming. Typically, a turnaround time of about $15 \mathrm{~min}$ is noted on average in acute care laboratories of most tertiary care hospitals for the above [2]. Quick decisions that need to be made depending on electrolyte values hence are often made either blindly or are delayed. Point-of-care testing for electrolytes is available from specialized equipment such as the iSTAT or Stat Profile Critical Care Xpress analyzers [3]. The operational cost of iSTAT and other similar equipment is a major deterrent to their utilization in developing systems of health care. Electrolytes are also measured during arterial blood gas analysis, but are traditionally rarely trusted for clinical decision-making because of the dearth of published 
research about the same. The arterial blood gas (ABG) machines and AA differ in several aspects as listed in Table 1 [4].

The United States Clinical Laboratory Improvement Amendment (US CLIA) 2006 [5] accepts a difference of $0.5 \mathrm{mmol} / 1$ in measured potassium, and $4 \mathrm{mmol} / 1$ in measured sodium, from the gold standard measure of standard calibration solutions.

Previous studies [6] that measured the accuracy of electrolyte values obtained by ABG machines concluded that the results from two different measurement technologies differed significantly for plasma sodium and chloride concentrations. These differences significantly affected the calculated anion gap and strong ion difference values.

Others have also found statistically significant differences in measures of $\mathrm{pH}$, potassium, and hematocrit between ABG machines and leading bench-top analyzers $[6,7]$.

Experts have cited theoretical reasons for these differences based on the chemical reactions employed in the AA and the auto-analyzers [8].

1. Dilution with heparin raises the volume of the sample, thereby lowering the value of the measured electrolytes on the ABG.

2. High volume of heparin itself binds the electrolytes, thereby lowering the value of measured electrolytes on the $\mathrm{ABG}$.

Our study had a null hypothesis that there is no difference between the electrolyte measurements by the $\mathrm{AA}$ and $\mathrm{ABG}$ machines.

\section{Materials and methods}

The study was approved by the ethics committee of Apollo Hospitals, Hyderabad, India. The study was designed to be

Table 1 Differences between the blood gas analyzer and auto-analyzer

\begin{tabular}{ll}
\hline Blood gas analyzer & Auto-analyzer \\
\hline $\begin{array}{l}\text { Analyzes whole blood } \\
\text { Arterial sample used } \\
\text { conventionally }\end{array}$ & $\begin{array}{l}\text { Analyzes serum } \\
\text { Venous sample used conventionally } \\
\text { Uses direct ion selective } \\
\text { electrode }\end{array}$ \\
$\begin{array}{l}\text { Uses heparin-diluted sample } \\
\text { technology }\end{array}$ & $\begin{array}{c}\text { Serum sample diluted with fixed } \\
\text { volume diluent }\end{array}$ \\
Processing time is short & Processing time is long \\
No effect of protein levels & Affected by protein levels in blood \\
in blood & \\
\hline
\end{tabular}

Table 2 Statistical analysis of sodium samples

\begin{tabular}{lll}
\hline Sample & Mean mmol/1 & SD \\
\hline Blood gas analyzer & 131.2 & 7.3 \\
Auto-analyzer & 136.4 & 6.5 \\
\hline
\end{tabular}

an observational study of a consecutive cohort of patients admitted to the ICU.

Paired blood samples from 200 consecutive adult patients admitted to the Medical ICU of Apollo Hospitals were included in the study. The study period started in August 2005 and ended in May 2006. Blood samples were collected simultaneously for ABG and AA for electrolyte analysis. All samples were analyzed on the ABL555 blood gas analyzer and the Dade Dimension RxL Max, both located in the central laboratory. Both of these are considered as benchmark top models in their respective technologies.

Quality control was ensured by having the blood samples collected by trained staff of a single ICU unit in the hospital and analyzed in the two analyzers located in the central laboratory under similar environmental conditions, unlike in the previous studies where the analyzers were in different environments [7]. Both analyzers were calibrated [10] according to the Joint Commission on Accreditation of Hospitals (JCAHO) requirements for hospital certification prior to each measurement cycle. Time of collection of samples was documented on both sample groups for reference. Operators drawing and handling blood samples did so with only latex gloves without using any hand disinfectants just prior to handling blood [11].

The 200 paired samples included a venous blood sample for auto-analyzer electrolyte measurement and an arterial blood sample for blood gas analysis.

Data were collected, and the values of sodium $(\mathrm{Na}+)$ and potassium $(\mathrm{K}+)$ from these measurements were compared using the paired $\mathrm{t}$-test.

\section{Results}

The analysis of sodium values (Table 2) showed that the mean sodium measured on the $\mathrm{ABG}$ was $131.28 \mathrm{mmol} / \mathrm{L}$ (SD 7.33), and the mean sodium measured by the AA was $136.45 \mathrm{mmol} / \mathrm{L}$ (SD 6.50). The maximum difference in sodium value was $30 \mathrm{mmol} / \mathrm{l}$, and the minimum difference was $0 \mathrm{mmol} / \mathrm{l}$. The mean difference was $5.96 \mathrm{mmol} / 1$ with SD 5.09 ( $p<0.001$, significant difference detected, hence null hypothesis rejected). The correlation coefficient (r) was 0.68 . The adjusted $r^{2}$ was within a $95 \%$ confidence interval from 
0.34 to 0.56 . It was noted that $86.5 \%$ of $\mathrm{Na}+$ values obtained on the ABG machine were lower than those on the AA.

Sodium analysis was stratified based upon the standard laboratory values, and 135-145 $\mathrm{mmol} / \mathrm{l}$ was considered as normal serum sodium. Anything above was considered hypernatremia. Patients with serum sodium 120-135 mmol/1 were considered as borderline hyponatremic, and patients with serum sodium less than $120 \mathrm{mmol} / \mathrm{l}$ were diagnosed as hyponatremic (Table 3). Clinically this was a more significant group because only at $\mathrm{Na}<120$ did the clinicians feel it important to correct sodium emergently.

Analysis of the sodium measurements in the group of patients with normal sodium revealed a significant difference between the two measures $(\mathrm{p}=0.005$; null hypothesis rejected). However, the mean difference between the two measuring methods was $3.4 \mathrm{mmol} / \mathrm{l}$, which was within the acceptable limit defined in the US CLIA 2006.

There was no significant difference in sodium measurements by $\mathrm{AA}$ and $\mathrm{ABG}$ for patients with hypernatremia (mean difference $3.8 \mathrm{mmol} / \mathrm{l} ; \mathrm{p}=0.3847$, null hypothesis accepted). However, because of the small sample size $(n=$ 5) in this subgroup, we were underpowered to detect a difference.

In the group of patients with borderline hyponatremia (serum sodium 120-135 mmol/l) and hyponatremia (serum sodium $<120 \mathrm{mmol} / \mathrm{l}$ ), the mean difference between the two measurements was $7.4 \mathrm{mmol} / 1$ and $12.8 \mathrm{mmol} / \mathrm{l}(\mathrm{p}<0.0001$ for both subgroups), effectively making the ABG measurements unreliable.

Analysis of the potassium values (Table 4) obtained from the AA and the ABG gave a mean difference of $0.46 \mathrm{mmol} / 1$ with a standard error of $0.03 \mathrm{mmol} / \mathrm{l}$. There was no significant difference ( $p=0.2679$, null hypothesis accepted) between $\mathrm{K}+$ measured by the ABG (3.7 mmol/l, SD 1.9) and AA (mean $3.9 \mathrm{mmol} / \mathrm{l}$, SD 1.8). The maximum difference in measured potassium value was $2.4 \mathrm{mmol} / \mathrm{l}$, and the minimum difference was $0 \mathrm{mmol} / \mathrm{l}$. The correlation coefficient (r) was 0.72 . The adjusted $\mathrm{r}^{2}$ was within a $95 \%$ confidence interval of 0.42 to 0.62 . A total of $71.5 \%$ of the $\mathrm{K}+$ values obtained on the ABG was lower than the AA.

Table 3 Stratified analysis of difference between $\mathrm{Na}+$ measured by $\mathrm{AA}$ and $\mathrm{ABG}$

\begin{tabular}{llllll}
\hline $\begin{array}{l}\text { Group } \\
\mathrm{mmol} / 1\end{array}$ & $\begin{array}{l}\text { Mean } \\
\text { difference } \\
\mathrm{mmol} / 1\end{array}$ & $\begin{array}{l}\mathrm{SD} \\
\text { difference } \\
\mathrm{mmol} / \mathrm{l}\end{array}$ & $\begin{array}{l}\text { Max. } \\
\text { difference } \\
\mathrm{mmo} / \mathrm{l}\end{array}$ & $\begin{array}{l}\text { Min. } \\
\text { difference } \\
\mathrm{mmol} / 1\end{array}$ & P value \\
\hline$>145$ & 3.8 & 2.77 & 8.0 & 1.0 & 0.3847 \\
$135-145$ & 3.4 & 2.35 & 12.0 & 0.0 & 0.0051 \\
$120-135$ & 7.4 & 4.26 & 22.0 & 0.0 & $<0.0001$ \\
$<120$ & 12.8 & 7.19 & 30.0 & 6.0 & $<0.0001$ \\
\hline
\end{tabular}

Table 4 Statistical analysis of potassium

\begin{tabular}{lll}
\hline Sample & Mean mmol/1 & SD mmol/1 \\
\hline Blood gas analyzer & 3.7 & 1.9 \\
Auto-analyzer & 3.9 & 1.8 \\
\hline
\end{tabular}

Potassium values were stratified (Table 5) based upon the standard laboratory values. Patients with $\mathrm{K}+3.5-$ $5.0 \mathrm{mmol} / \mathrm{l}$ were normo-kalemic, values above $5.0 \mathrm{mmol} / \mathrm{l}$ were considered as hyperkalemia, and those below $3.5 \mathrm{mmol} / 1$ were considered as hypokalemia.

The mean differences in patients with hyperkalemia, normokalemia, and hypokalemia were $0.44 \mathrm{mmol} / 1$ (SD 0.05 ), $0.46 \mathrm{mmol} / 1$ (SD 0.03), and $0.42 \mathrm{mmol} / 1$ (SD 0.02), respectively, all of which are less than the US CLIA 2006 guideline of $0.5 \mathrm{mmol} / \mathrm{l}$.

\section{Discussion}

Point-of-care analyzers are force multipliers for clinicians working in the areas of critical care and emergency medicine. They have been proven to benefit clinical decision-making by reducing the turnaround time for routine biochemical investigations. Time critical decisions are enabled by point-of-care analyzers when biochemical parameters are beyond their normal limits. Several kinds of point-of-care testing equipment are in vogue in clinical practice today, and they have been widely evaluated in varied environments.

Point-of-care testing has gained special favor in emergency transport systems, critical care departments, and cardiothoracic surgical departments, as is shown by the large volume of systems developed for all of these areas [12-14].

However, high operational costs are a deterrent to the application of specialized point-of-care equipment in developing countries [15]. Direct costs have been decreasing

Table 5 Stratified analysis of the difference between $\mathrm{K}+$ measured by $\mathrm{AA}$ and $\mathrm{ABG}$

\begin{tabular}{llllll}
\hline $\begin{array}{l}\text { Group } \\
\mathrm{mmol} / 1\end{array}$ & $\begin{array}{l}\text { No. of } \\
\text { values }\end{array}$ & $\begin{array}{l}\text { Mean } \\
\text { difference } \\
\mathrm{mmol} / \mathrm{l}\end{array}$ & $\begin{array}{l}\mathrm{SD} \\
\text { difference } \\
\mathrm{mmol} / \mathrm{l}\end{array}$ & $\begin{array}{l}\text { Max. } \\
\text { difference } \\
\mathrm{mmo} / \mathrm{l}\end{array}$ & $\begin{array}{l}\text { Min. } \\
\text { difference } \\
\mathrm{mmol} / 1\end{array}$ \\
\hline$>5.0$ & 58 & 0.44 & 0.05 & 1.8 & 0.0 \\
$3.5-5.0$ & 106 & 0.46 & 0.03 & 1.6 & 0.0 \\
$<3.5$ & 36 & 0.42 & 0.02 & 2.4 & 0.0 \\
\hline
\end{tabular}


as the supply of such analyzers increases. The aim of the study was to evaluate existing point-of-care arterial blood gas analyzers for electrolyte measures. The instrumental difference between the $\mathrm{AA}$ and the $\mathrm{ABG}$ analyzers is the turnaround time to get the results. Also the fact that blood gas analyzers are unaffected by serum protein levels in their electrolyte measures is an added advantage to using them as a point-of-care electrolyte measure in critically ill patients $[16,17]$.

Despite the differences that have been cited in the working of the ABG machine and the AA, this study shows that there are no significant differences between the $\mathrm{K}+$ measured by the AA and the ABG machines. The authors therefore suggest that decisions based on serum $\mathrm{K}+$ can be made by trusting the value obtained on the ABG machine.

The study agrees with previous studies [6] that $\mathrm{Na}+$ values obtained on the $\mathrm{ABG}$ machine are not completely reliable when making clinical decisions. Though statistically significant, the difference in the measured $\mathrm{Na}+$ values in hypernatremic and normo-natremic patients was within the recommended US CLIA guidelines. Whether statistical difference also translates to clinical difference remains to be seen.

Some of the limitations of our study are that the results are limited to the use of one $\mathrm{AA}$ and one $\mathrm{ABG}$ machine. However, previous studies comparing blood gas analyzers of different brands have shown that the measures obtained from ABG machines are highly statistically concordant [18].

Another limitation was that the $\mathrm{ABG}$ samples were collected using conventional syringes containing liquid heparin. The use of dried heparin syringes [9] could improve the accuracy of the results by decreasing the dilution of the sample.

Previous studies referenced earlier have shown that ABG machines do not measure electrolytes accurately, but since all these studies compared results between $\mathrm{AA}$ and $\mathrm{ABG}$ analyzers in different environments, we created another limitation for ourselves by locating the ABG analyzer in the central laboratory in an environment similar to the AA, and in doing so we did undermine the true meaning of point-of-care testing, which is often equated to bed-side testing. However, the time gain was significant even by following the above practice since the time for analysis itself was minimized.

In conclusion, we advocate the use of $\mathrm{ABG}$ machines for adjudging serum potassium values accurately, in the absence of other specialized point-of-care analyzers. Further research is needed to establish their accuracy for sodium values.
Conflicts of interest None.

\section{References}

1. Price CP (2002) Medical and economic outcomes of point of care testing. Clin Chem Lab Med 40:246-251

2. Cox CJ (2001) Acute care testing. Bood gases and electrolytes at the point of care. Clin Lab Med. 21(2):321-335

3. Flegar-Mestric Z, Perkov S (2006) Comparability of point of care whole blood electrolyte and substrate testing using a Stat Profile Critical Care Xpress analyzer and standard laboratory methods. Clin Chem Lab Med 44(7):898-903

4. Pungor E (1992) Working mechanism of ion-selective electrodes. Pure \& Appl. Chem 64(4):503-507

5. The United States Clinical Laboratory Improvement Amendments

6. Morimatsu H, Rocktäschel J, Bellomo R, Uchino S, Goldsmith D, Gutteridge G (2003) Comparison of point-of-care versus central laboratory measurement of electrolyte concentrations on calculations of the anion gap and the strong ion difference. Anesthesiology 98:1077-1084

7. Prichard JS, French JS, Alvar N (2006) Clinical evaluation of the ABL-77 for point of care analysis in the cardiovascular operating room. J Extra Corpor Technol 38(2):128-133 Jun

8. Jacobs E, Ancy JJ, Smith M (2002) Multi site performance evaluation of $\mathrm{pH}$, bood gas, electrolyte, glucose and lactate determinations with the GEM Premier 3000 critical care analyzer. Point of Care 1:135-144

9. Rouse C. Theoretical reasons for sodium measurement error POCT specialist -C29-A2 ISBN 1-56238-410-4 ISSN 0273-3099

10. Standardization of sodium and potassium ion-selective electrode systems to the flame photometric reference method; Approved Standard-Second Edition NCCLS.

11. Lam HS, Chan MH, Ng PC, Wong W, Cheung RC, So AK, Fok TF, Lam CW (2005) Are your hands clean enough for point of care electrolyte analysis? Pathology 37(4):299-304 Aug

12. Steinfelder-Visscher J, Weerwind PW, Teerenstra S, Pop GA, Brouwer RM (2007) Conductivity based hematocrit meaurement during cardiopulmonary bypass. J Clin Monit Comput 21(1):7-12 Epub 2006 Nov 4, Feb

13. Vos G, Engel M, Ramsay G, van Waardenburg D (2006) Point of care blood analyzer during interhospital transport of critically ill children. Eur J Emerg Med 13(5):304-307 Oct

14. Myers GJ, Browne J (2007) Point of care hematocrit and hemoglobin in cardiac surgery: a review. Perfusion 22:179-183

15. Magny E, Beaudeux JL, Launay JM (2003) Point care testing in blood gas and electrolyte analysis: examples of implementation and cost analysis. Ann Biol Clin (Paris) 61(3):344-351 May-Jun

16. Dimeski G, Barnett RJ (2005) Effects of total plasma protein concentration on plasma sodium, potassium and chloride measurements by an indirect ion selective electrode measuring system. Crit Care Resusc 7(1):12-15 Mar

17. Chow E, Fox N, Gama R (2008) Effect of low serum total protein on sodium and potassium measurement by ion-selective electrodes in critically ill patients. Br J Biomed Sci 65(3):128-131

18. Daures MF, Combescure C, Cristol JP (2007) Comparitive study of siz blood gas analyzers. Ann Biol Clin (Paris) 65(5):505-518 